\title{
Univocity, Duality, and Ideal Genesis: Deleuze and Plato
}

\author{
John Bova and Paul M. Livingston
}

In Difference and Repetition, Gilles Deleuze outlines a theory of ideas as problems, existent on the level of a virtuality distinct from, but irreducibly related to, that of their incarnation in a variety of specifically constituted theoretical domains:

Following Lautman and Vuillemin's work on mathematics, 'structuralism' seems to us the only means by which a genetic method can achieve its ambitions. It is sufficient to understand that the genesis takes place not between one actual term, however small, and another actual term in time, but between the virtual and its actualisation - in other words, it goes from the structure to its incarnation, from the conditions of a problem to the cases of solution, from the differential elements and their ideal connections to actual terms and diverse real relations which constitute at each moment the actuality of time. This is a genesis without dynamism, evolving necessarily in the element of a supra-historicity, a static genesis which may be understood as the correlate of the notion of passive synthesis, and which in turn illuminates that notion. ${ }^{1}$

Deleuze's identification of ideas with problems is adopted, in part, from the novel synthesis proposed by the mathematical philosopher Albert Lautman in a series of essays of the 1930s and 40s, between an unorthodox but textually-grounded Platonism and the mathematics of his time. ${ }^{2}$ Deleuze takes Lautman's work to provide at least partial means for a reconciliation of structure and genesis, so that an account of the virtual structure of an idea-problem can at the same time, and without irreducible tension, function as an account of its real genesis in a specific, concrete domain. This yields Deleuze's understanding of ideal genesis, which involves at once an account of the origin of "actual terms and diverse real relations" and an account of the origin of those "differential elements and ideal connections" that precede and determine them. The principle underlying both origins is that of a paradoxical structural becoming which realizes the concrete relations characteristic of a particular field on the basis of a prior "dialectic" of formal/structural relationships, in particular those of limit, unlimitedness, multiplicity and unity.

In this essay, we will consider the formal and ontological implications of one specific and intensely contested dialectical context from which Deleuze's thinking about structural ideal genesis visibly arises. This is the formal/ontological dualism between the principles, ( $\alpha \rho \alpha \alpha i)$, of the One (žv) and the

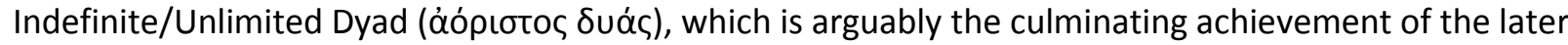
Plato's development of a mathematical dialectic. ${ }^{3}$ Following commentators including Lautman, Oskar Becker, and Kenneth M. Sayre, we argue that the duality of the One and the Indefinite Dyad provides, in the later Plato, a unitary theoretical formalism accounting, by means of an iterated mixing without

\footnotetext{
${ }^{1}$ Deleuze (1968), p. 183, translation slightly modified.

${ }^{2}$ Anglophone study of this neglected philosopher was jumpstarted by Simon Duffy's 2011 translation of Lautman's collected works, Lautman (2011). Recent studies of Lautman in relation to Deleuze include Duffy (2009), Kaufman (2012), and Duffy (2013)

${ }^{3}$ Note that one should not be misled by parallel structure when naming the principles. The One is probably not best identified with "limit" ( $\pi \dot{\varepsilon}$ pas) but with the formal cause of the limit, which is at the same time the limit of limit's power to distinguish itself from the unlimited, if indeed the Good is what causes the mix, as Lautman would say, of limit and unlimited in the Philebus. For the One to appear as limit already requires the presence of the Dyad as that in which limits can come to be; thus it is already to be working on the plane of participation-instances. Similarly, it is the implicit identification of the indefinite negation "unlimited" with the positive content, "Dyad" or "great-and-small" which is dialectically provocative in Plato's naming of that principle.
} 
synthesis, for the structural origin and genesis of both supersensible Ideas and the sensible particulars which participate in them. As these commentators also argue, the duality furthermore provides a maximally general answer to the problem of temporal becoming that runs through Plato's corpus: that of the relationship of the flux of sensory experiences to the fixity and order of what is thinkable in itself. Additionally, it provides a basis for understanding some of the famously puzzling claims about forms, numbers, and the principled genesis of both attributed to Plato by Aristotle in the Metaphysics, and plausibly underlies the late Plato's deep considerations of the structural paradoxes of temporal change and becoming in the Parmenides, the Sophist, and the Philebus.

After extracting this structure of duality and developing some of its formal, ontological, and metalogical features, we consider some of its specific implications for a thinking of time and ideality that follows Deleuze in a formally unitary genetic understanding of structural difference. These implications of Plato's duality include not only those of the constitution of specific theoretical domains and problematics, but also implicate the reflexive problematic of the ideal determinants of the form of a unitary theory as such. We argue that the consequences of the underlying duality on the level of content are ultimately such as to raise, on the level of form, the broader reflexive problem of the basis for its own formal or meta-theoretical employment. We conclude by arguing for the decisive and substantive presence of a proper "Platonism" of the Idea in Deleuze, and weighing the potential for a substantive recuperation of Plato's duality in the context of a dialectical affirmation of what Deleuze recognizes as the "only" ontological proposition that has ever been uttered. This is the proposition of the univocity of Being, whereby "being is said in the same sense, everywhere and always," but is said (both problematically and decisively) of difference itself.

\section{Becoming and the Dyad: Deleuze's Plato}

In the opening pages of The Logic of Sense, Deleuze considers the structure of a pure and paradoxical "becoming whose characteristic is to elude the present." ${ }^{4}$ This becoming is exemplified, according to Deleuze, by the "pure events" of Alice's transformations in Alice's Adventures in Wonderland and Through the Looking-Glass. It involves an "essence of becoming" through which it moves unlimitedly in both of two opposed directions at once, Alice becoming (for example) in the same moment both larger than she was and smaller than she becomes. According to Deleuze, this paradoxical and bidirectional structure provides the formal basis for a theory of the conditioning of phenomena that, including their change and becoming at a fundamental level, does not relegate this conditioning to the static resemblance between a model and its copy. As yielding such a theory of conditioning, the structure of paradoxical and unlimited becoming also helps to define an original structure of genesis, at the formal basis of the virtual which is the "characteristic state of Ideas." ${ }^{5}$ Indeed, as Deleuze goes on to suggest, the structure of unlimited becoming is opposed, already in Plato, to the dimension of fixity, measure, and rest. The two produce a profound and deep dualism at the root of Plato's understanding of temporal genesis, one that is to be sharply distinguished from the more familiar "dualism" of the sensible and the supersensible:

Plato invites us to distinguish two dimensions: (1) that of limited and measured things, of fixed qualities, permanent or temporary which always presuppose pauses and rests, the fixing of presents, and the assignation of subjects ... and (2) a pure becoming without measure, a veritable becoming-mad, which never rests. It moves in both directions at once. It always

\footnotetext{
${ }^{4}$ Deleuze (1969), p. 1.

${ }^{5}$ Deleuze (1968), p. 111.
} 
eludes the present, causing future and past, more and less, too much and not enough to coincide in the simultaneity of a rebellious matter. ${ }^{6}$

Deleuze quotes briefly two passages in which this problematic becoming is evidenced in Plato's dialogues, in connection with the problem of the relationship of temporal flux, change, and becoming, limitless in itself, to whatever fixes quantities and gives order. The first of these is Socrates' example in the Philebus (24b-d) of the hotter and the colder, which cannot (as Socrates argues) "take on a definite quality" since, as they are always "going a point further," cannot stop and become fixed without becoming something other than themselves. This requires, according to Socrates, that both the hotter

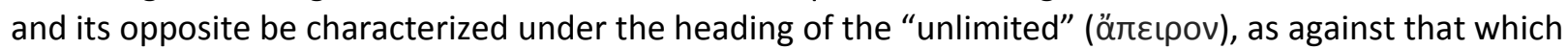
is characterized, by contrast, by "limit," ( $\pi \dot{\varepsilon} \rho \varsigma \varsigma$ ) in the course of drawing a distinction among everything that is into these two types, along with their mixture and its cause, the principle of which is established earlier in the dialogue as one suggested or given by the gods. The other example comes in the Parmenides, in the course of the development of the implications of the second hypothesis about the One, and in particular the consequences of its partaking in time. According to this hypothesis, Parmenides suggests, the One will be characterized by "coming-to-be both older and younger, and neither older nor younger, than the others and they than it." (154a). By virtue of this becoming, according to Parmenides, both younger and older go "toward their opposites... the younger coming to be older than the older, and the older younger than the younger..." though neither, again, can actually attain a fixed relationship to the other, since then they would cease becoming and no longer come to be anything at all.

In thus evoking the duality between a dyadic principle of unlimited becoming, on one hand, and the fixity of limit, on the other, Plato thus points, according to Deleuze, to a "more profound and secret dualism hidden in sensible and material bodies themselves," one that does not characterize the distinction between the "intelligible and the sensible," between "Idea and matter" or between "Ideas and bodies." ${ }^{7}$ Rather, it is a dualism between "that which receives the action of the Idea and that which eludes this action," according to which, while "limited things lie beneath the Ideas," there is nevertheless still "even beneath things...[a] mad element which subsists and occurs on the other side of the order that Ideas impose and things receive." ${ }^{8}$ This Platonic dualism between (on the one hand) what Plato characterizes as the One or Unity and (on the other) an irreducibly dyadic principle of the unlimited, further characterized as that of the "Great and the Small" thus offers, on Deleuze's reading, a general structural framework for accounting not only for the relationship of "participation" between sensible things and Ideas, but even for the very constitution of both on the basis of the deeper structural and dialectical relationships it formulates.

It is the same Platonic dualism which, as modern scholarship has demonstrated, plausibly underlies some of the puzzling views about forms and numbers attributed elliptically to Plato by Aristotle in the course of his doxography of earlier principles in the Metaphysics:

Since the Forms are the causes of all other things, [Plato] thought their elements were the elements of all things. As matter, the great and the small were principles; as substance, the One; for from the great and the small, by participation in the One, come the Forms, i.e. the numbers.

\footnotetext{
${ }^{6}$ Deleuze (1969), pp. 1-2.

${ }^{7}$ Deleuze (1969), p. 2.

${ }^{8}$ Deleuze (1969), p. 2.
} 
But he agreed with the Pythagoreans in saying that the One is substance and not a predicate of something else; and in saying that the numbers are the causes of the substance of other things, he also agreed with them; but positing a dyad and constructing the infinite out of great and small, instead of treating the infinite as one, is peculiar to him; and so is his view that the numbers exist apart from sensible things, while they say that the things themselves are numbers, and do not place the objects of mathematics between Forms and sensible things. His divergence from the Pythagoreans in making the One and the numbers separate from things, and his introduction of the Forms, were due to his inquiries in the region of definatory formulae (for the earlier thinkers had no tincture of dialectic), and his making the other entity besides the One a dyad was due to the belief that the numbers, except those which were prime, could be neatly produced out of the dyad as out of a plastic material. ${ }^{9}$

In this passage and others, Aristotle attributes several deeply puzzling claims to Plato. These include the claims that Forms have elements which are also the elements "of all things", that numbers can be "produced out" of the dyad of the Great and Small, which acts as a kind of "material" in combination with the One, and that forms actually are themselves to be identified with numbers as thus produced. Aristotle appears also to claim that Plato held that sensible objects are constituted of forms and the Great and the Small, and that forms are themselves composed of the Great and the Small together with Unity. ${ }^{10}$ Aristotle says directly in several places that Plato identified forms with numbers. ${ }^{11}$ He also makes the suggestions that Plato identifies Unity with the Good (and perhaps that he identifies the Great and the Small, by contrast, with evil), and that Plato treats the "Great and Small" as matter with respect to which the One is form. ${ }^{12}$

Beyond Aristotle's testimony, there is evidence that the development of the problem of number may be closely connected with the content of what have been called Plato's "unwritten" teachings. ${ }^{13}$ The sixthcentury Neoplatonist Simplicius notoriously reports descriptions of a lecture given by Plato on the Good and attended by Aristotle and others: Aristotle is said to have reported Plato's teaching that the principles of all things, including the Ideas, are the "Indefinite Dyad, which is called Great and Small" and Unity. ${ }^{14}$ There is a suggestion in Simplicius's quotations of Poryphry and Alexander that Plato had held that Unity and the Indefinite Dyad are also the elements of numbers and that each of the numbers participates in these two principles. ${ }^{15}$ The lecture on the Good is said by Aristotle's student Aristoxenus to have confounded Plato's listeners, who expected a lecture on ethics but were instead treated to a discussion of numbers and geometry, leading up to the claim that the Good is to be identified with Unity or "the One". ${ }^{16}$ In Platonic scholarship, the attempt to explicate the exact nature and systematic role of the teachings of Plato that can be summarized under the heading of the duality of the $\alpha \rho x \alpha$ i of the One/Good and the indefinite dyad, or the greater-and-less have led to a wide variety of exegetical and

\footnotetext{
${ }^{9}$ Metaphysics 1.6:987b14-987b35. Translation altered. Ross notes that this reading of the end of the first paragraph, "come the forms, i.e., the numbers", and not merely "come the numbers", is the one in accordance with the Greek of the manuscripts.

${ }^{10}$ These claims are suggested by the continuation of the passage quoted above: Metaphysics 988a10-17. For discussion, see Sayre (2005), pp. 90-94.

${ }^{11}$ E.g. Metaphysics 991b9, De Anima 404b24.

${ }_{12}$ Metaphysics 988a7-17; Metaphysics 1091b13-14; Physics 187a17.

${ }^{13}$ Aristotle refers to Plato's "so-called unwritten teachings" at Physics 209b14-15.

${ }^{14}$ For references and discussion, see Sayre (2005), pp. 76-77.

${ }^{15}$ Sayre (2005), p. 77.

${ }^{16}$ Sayre (2005), p. 77.
} 
substantive accounts. ${ }^{17}$ Many of these accounts have attempted, as well, to explain why these apparently crucial teachings do not appear in a direct form in any of Plato's dialogues, characterizing them, for instance, as Plato's "oral" or "inner-Academic" teachings, or emphasizing what is seen as their intrinsic connection to a dialogical form of life, which for various reasons cannot be directly represented or replicated in writing. Here, without taking a position on this question of the "unwrittenness" of the theory of duality, we will simply attempt to reconstruct its probable logical form, following in particular modern commentators who discover evidence for it in the dialogues themselves.

In particular, it will be useful to consider the interpretations of the doctrine of duality which arise in the twentieth century from two rather disparate lines of scholarship. One of these lines, arising from Julius Stenzel and passing through Oskar Becker, culminates in Lautman's reconstruction of the ideal genesis of numbers and ideas on the basis of a "superior" dialectic of virtual relations. It is this line which, as we have already seen, most directly influences Deleuze in his conception of ideal genesis on the level of the virtual. But another strand, largely or wholly distinct from the first but just as useful for understanding the probable logical form of Plato's doctrine, is inaugurated in recent "analytic" scholarship by Kenneth M. Sayre's interpretation of the so-called "unwritten teachings" as, in fact, literally written in several of the late dialogues, and explicable on the direct basis of the mathematical theories and leading problems already known to Plato.

\section{The Principles in the Twentieth Century: Stenzel, Becker, Lautman, and Sayre}

In his 1927 work Mathematical Existence, Oskar Becker, following Julius Stenzel, theorizes the role of the

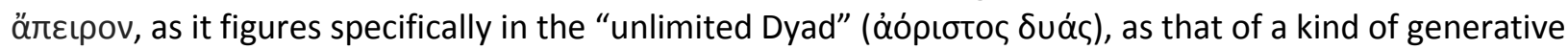
potency, at the root of both the existence of "number" and its "generation" in accordance with a temporal or quasi-temporal anteriority to produce an ordering of before and after. Becker suggests that this ordering is subsequently crucial for Aristotle's conception of the infinite, and in particular for its close relationship to his account of time in the Physics, according to which time is a counting or numbering of motion, with respect to just this distinction of "before and after." Here, Becker suggests, the thought of time as the continuity of the örcเpov, prior to and before the possibility of measurement, has a deeper provenance in the linked conception of time and number already appears in the somewhat obscure Platonic conception of the dyad. ${ }^{18}$ In a later (1931) article "The Diairetic Generation of Platonic Ideal Numbers," Becker, developing suggestions made initially by Stenzel, argues that the generation of numbers can be considered, in close connection with the method of "diaeresis" or division recommended by Plato in a number of late dialogues, actually identical to that of the diairetic definition of a concept by division. Stenzel had suggested, in particular, that the positive whole numbers may be seen as generated by means of a process of successive binary "division," whereby each number $n$, beginning with 1 , generates $2 n$ and $2 n+1$. According to Becker, although this solution tends in the right direction, it does not explain how "ideal" (as opposed to familiar mathematical) numbers can actually be ideas, and it also does not explain how ideas can thereby be thought as dynamically generated rather

\footnotetext{
${ }^{17}$ There is more than one way in which a list of theses can be compiled from these prose accounts. For some examples see Sayre (2005), pp. 94-95, and also Miller (1995), and Nikulin (2012). The last also contains an overview of the secondary evidence for the existence of Plato's thought on the principles, for a fuller archive of which see Gaiser's Testimonia Platonicum, in Greek and German at the end of Gaiser (1963) and Findlay's selections, in English, appended to Findlay (1974). Sayre's argument depends upon establishing the strength of a chain of synonyms for the Dyad. He maintains a list of their incidence in the commentators at http://www3.nd.edu/ philinst/plato.html.

${ }^{18}$ Becker (1927) 6.b.i.C
} 
than simply recovered subsequently by analysis. As an alternative, he suggests that the ideal numbers are generated by a repeated process whereby one divides into two, but in the division the original one is "sublated" or overcome in the division. In this way, the powers of $2(2,4,8,16$, etc.) can be thought of as generated by the symmetrical iteration of binary division itself, while all other numbers are seen as arising from an asymmetrical development of a diairetic tree structure (e.g. 3 is generated by the division of an initial unit, $a$, into two, ( $b$ and $c$ ) and the subsequent division of $c$ into $d$ and $e$, while $b$ remains unaffected; the remaining (unsublated) elements are then three (b, $d$, and e).) In this way, the actual seriality of number can be seen as generated in a way that is "formally identical" to the structure of the diairesis of concepts that Plato suggests in the Sophist and the Statesman. Becker also notes the possibility of connecting this to the structure of the division of a continuous quantity by iterated fractional decomposition to produce an exact (rational) point. In this way, the process of diairesis which results in the identification of the constituents of an idea as "monads" or "ones" may be thought to produce examples of the sort that Plato appeals to in the Philebus, e.g. the identification of the fixed letters or discrete musical notes from the fluid continuum of possible sounds.

Albert Lautman's 1939 work, "New Research on the Dialectical Structure of Mathematics," draws on the thesis of his 1938 dissertation, according to which concrete mathematical theories develop a series of "ideal relations" of a "dialectic abstract and superior to mathematics." ${ }^{19}$ In particular, Lautman understands abstract "dialectical" ideas as the development of the possibility of relations between what he calls (by contrast) pairs of notions: these are pairs such as those of "whole and part, situational properties and intrinsic properties, basic domains and the entities defined on these domains, formal systems and their realization, etc." ${ }^{20}$ The dialectical ideas that pose these relations do not presuppose the existence of specific mathematical domains or objects. Rather, they operate, in the course of mathematical research, essentially as "problems" or "posed questions" that provide the occasion for inquiry into specific mathematical existents. In reference to differing specific mathematical theories such as, for instance, the theory of sets or (in a different way) real analysis, the dialectical relationship of whole and part may be seen as posing a general problem which is to be resolved differently in each domain, on the basis of concrete mathematical research, and thereby partially determines the kind and structure of entities existing in that particular domain. Thus general problems such as the problem of the relationship of formal theories of proof to actual mathematical results, the relationship of whole to part, and (especially) the relationship of continuity and discontinuity pose conditions under which they are resolved concretely, in different ways, in specific mathematical theories. At the same time, the development of the specific theories in terms of the particular kinds of structures and entities said to exist therein points back to the general problem and articulates its own more general structure.

The problem, here, thus has a priority over its particular solutions, and cannot be reduced to them. According to Lautman, this priority is not that of an ideality existent in itself prior to its incarnation in a specific domain, but rather that of the kind of problematic "advent of notions relative to the concrete within an analysis of the Idea." ${ }^{21}$ In particular, it is only in developing the actual structure and configuration of particular concrete domains, that the actual meaning of the governing Ideas is worked out. Here the concrete development of particular domains does not, moreover, exhaust the general problem but rather, typically, suggests new questions and problems in other concrete domains which are also to be related to the same general dialectical structure. Dialectical Ideas, in this sense, "govern" the "intrinsic reality" of mathematical objects and it can even be said, using the Platonic terminology,

${ }^{19}$ Lautman (1939), p. 199. He refers here to Lautman (1938).

${ }^{20}$ Lautman (1939), p. 204.

${ }^{21}$ Lautman (1939), p. 200. 
that the reality of the mathematical objects, as concretely demonstrated in mathematical research, thus resides in their "participation" in the dialectical ideas. ${ }^{22}$ But as Lautman emphasizes, this sense of "participation" is quite at odds with the way Plato's conception of participation is typically understood. In particular, whereas participation is often understood as that of an ideal model to objects which in some respect copy them, here the Ideas are understood "in the true Platonic sense of the term" as the "structural schemas according to which the effective theories are organized." ${ }^{23}$ What is at issue here is not a "cosmological sense" of the relationship between ideas and their concrete realization such as is developed, for instance, in the Timeaus. According to such a sense, which is fundamentally understood by reference to the concept of creation as forming or shaping, the realization of the ideas in concrete reality depends on their capacity to impose law and structure on an otherwise undifferentiated matter, itself knowable only (as Plato in fact suggests) by a kind of "bastard reasoning" or "natural revelation." 24 By contrast with this "cosmological sense" of the relationship between ideas and particulars, it is essential in the case of mathematical objectivity to understand the relationship between the dialectical ideas and the particular mathematical objects as a "cut [which] cannot in fact be envisaged." This is, Lautman says, a kind of "mode of emanation" from dialectics to mathematics that does not in any way presuppose the "contingent imposition of a Matter heterogeneous to the Ideas." ${ }^{25}$

For Lautman, many of the problems that define the "superior" dialectic that ultimately determines specific mathematical domains and their essential problems are evident in the historical concerns of philosophers, for instance with the relationships between the "same and the other, the whole and the part, the continuous and the discontinuous, essence and existence." ${ }^{26}$ But the mathematician's activity has an equally significant role, according to Lautman, in giving rise to new problems that have not yet been abstractly formulated. In this twofold enterprise, the task is thus not to demonstrate the applicability of classical logical or metaphysical problems within mathematical theories, but rather to grasp the structure of such theories "globally in order to identify the logical problem that happens to be both defined and resolved" by its existence. ${ }^{27}$ This is a peculiar experience of thought, according to Lautman, equally characteristic of the capacity of the intelligence to create as of its capacity to understand. In it,

Beyond the temporal conditions of mathematical activity, but within the very bosom of this activity, appear the contours of an ideal reality that is governing with respect to a mathematical matter which it animates, and which however, without that matter, could not reveal all the richness of its formative power. ${ }^{28}$

Finally, Lautman suggests that this particular experience of exigency, by means of which general philosophical problems communicate with the particular constraints of specific mathematical domains to illuminate the "contours" of such a superior reality, can be witnessed in the late Plato's understanding of the genesis of Ideas and numbers:

\footnotetext{
${ }^{22}$ Lautman (1939), p. 199.

${ }^{23}$ Lautman (1939), p. 199.

${ }^{24}$ Lautman (1939), p. 199.

${ }^{25}$ Lautman (1939), pp. 199-200.

${ }^{26}$ Lautman (1938), p. 189.

${ }^{27}$ Lautman (1938), p. 189.

${ }^{28}$ Lautman (1938), p. 190.
} 
All modern Plato commentators ... insist on the fact that the Ideas are not immobile and irreducible essences of an intelligible world, but that they are related to each other according to the schemas of a superior dialectic that presides over their arrival. The work of Robin, Stenzel and Becker has in this regard brought considerable clarity to the governing role of Ideasnumbers which concerns as much the becoming of numbers as that of Ideas. The One and the Dyad generate Ideas-numbers by a successively repeated process of division of the Unit into two new units. The Ideas-numbers are thus presented as geometric schemas of the combinations of units, amenable to constituting arithmetic numbers as well as Ideas in the ordinary sense. ${ }^{29}$

Following Stenzel and Becker, Lautman suggests that the diaeretic "schemas of division" of Ideas in the Sophist can themselves be traced, in their logical structure, to the schemas of the "combination of units" that are also responsible for the generation of the ideas-numbers. Both are then genetically dependent upon a kind of "metamathematics" which unfolds a time of generation that, though it is not "in the time of the created world" is nevertheless, just as much, ordered according to anteriority and posteriority. ${ }^{30}$ This ordering according to anteriority and posteriority is equally determinative, and even in the same sense, with respect to essences quite generally as with respect to numbers themselves. Indeed, following a suggestion by Stenzel, Lautman suggests that this is the significance of Aristotle's claim in the Nicomachean Ethics (1.4) that the Platonists did not admit the ideas of numbers. Since the idealnumbers are already the principle of the determination of essences as anterior and posterior (i.e. as before and after), there is not (nor can there be) a further principle of the division of essences that is prior to or superior to this numerical division itself. In this impossibility of equipping the metamathematics of the ideal-numerical principles of anteriority and posteriority with another determination (a "metametamathematics", so to speak), we witness once again, according to Lautman, the necessity of pursuing the dialectic in which the mathematical problems and the ideal relations communicate with and articulate one another. ${ }^{31}$ In particular, in such a dialectic, and only in it, are to be found the problematic conditions and the possibility of mutual illumination in which the more original structures constitutive of anteriority and posteriority as such - and hence of time and genesis, in an original sense - can be brought to light.

In a remarkable analysis, Kenneth $\mathrm{M}$. Sayre has argued that the content of the so-called "unwritten teachings" that link the problems of number with those of the structure of forms and the Good can be largely recovered from Plato's middle and late dialogues themselves. According to Sayre, it is thus not necessary to speculate about the esoteric content of the Platonic teachings alluded to by Aristotle, since they are actually present in dialogues such as the Philebus, Parmenides, and Sophist (among others). Sayre reconstructs Aristotle's statements as clearly attributing five distinct claims about forms, sensible objects, numbers, and the Great and the Small. Among these are the claims that sensible objects are constituted of forms and the Great and the Small, and that forms are themselves composed of the Great and the Small and Unity. ${ }^{32}$ As Sayre notes, while the claim that the forms are the principles or causes of sensible things is familiar from many of Plato's dialogues and is present as early as the Phaedo, the suggestion of a composition of the forms themselves by more basic principles would be, if it can be attributed to him, a significantly novel element of the late Plato's final thinking about them. Sayre sees this late conception as developed both thematically and methodologically in Plato's descriptions of the method of dialectic in the Sophist, the Statesman, and especially the Philebus, where at 16c-e, Socrates

\footnotetext{
${ }^{29}$ Lautman (1939), p. 190.

${ }^{30}$ Lautman (1939), p. 190.

${ }^{31}$ Lautman (1939), p. 191.

${ }^{32}$ Sayre (2005), p. 161.
} 
describes a "god-given" method for pursuing problems of the one and the many generally, including (it appears) with respect to the distinctive unity exhibited by forms. On Sayre's reading, the passage is meant to formulate a methodological response to the question of how the kind of unity (monadas) that a form is can characterize indefinitely many changing particulars, without thereby becoming dispersed among them and losing its unity. The problem is a specification of the more general question of how the properties and characteristics of individuals are thinkable at all, given that they are subject to ceaseless change in time.

Thus specified, the problem does not simply involve the unity of forms as such, over against sensible beings thought as completely undifferentiated or irreducibly multiple. Rather, since it is also the question of how sensible things are themselves thinkable as enduring unities despite the unlimitedness of their possible change, its solution involves a unified accounting for the unity of both. Since sensory objects would, if (somehow) deprived of the relationship to Forms that allow them to be thought as distinct individuals having definite characteristics, also have no definite character and in this sense be indistinguishable from the äreıрov, the problem is that of characterizing how determinate forms are themselves defined and gain application to the changing particulars. ${ }^{33}$ The elements of a solution to this are to be found, Sayre suggests, in the Philebus' development of cases (17a-e) in which a number of specific characteristics are distinguished out of a continuum of possible variation, such as the identification of particular letters from the continuum of vocables, or the identification of discrete musical notes from the continuum of sound. ${ }^{34}$ In this way, a particular discrete number of intermediate forms are introduced between the general and continuous form (for instance sound itself) and the specific instances, for which the intermediate forms then serve as measures. ${ }^{35}$

As Sayre suggests, the methodology may be considered a further development of the method of the collection or division (or synthesis and diaeresis) proposed in the Statesman and the Sophist. As is suggested there, the key methodological idea is that the definition of a thing begins by collecting a number of instances of the kind to be defined with a view to discerning the general form they have in common. The form, once found, is further articulated or qualified by a repeated diaeresis or division of its several components, until a unique set of specific characteristics is identified that distinguish the particular kind of thing in question from others similar to it. As Sayre notes, however, the major and glaring difference between the description of the "god-given" method in the Philebus and the descriptions of the dialectician's art in the Sophist and the Statesman is that the latter two involve no mention either of the örcเpov, or of the need to distinguish among indefinitely many single things to articulate what is in itself a continuum having the character of the "unlimited" in the sense of indefiniteness. Sayre sees the account given in the Philebus as responding to a problem about unity and

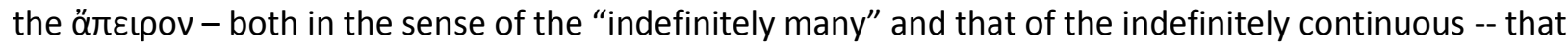
is already posed in the Parmenides at $157 \mathrm{~b}-158 \mathrm{~b}$. The idea of a unified collection of individual members, or a whole composed of parts, involves both that there is a sense of unity characteristic of the collection as a whole and that there is a sense of unity characteristic of each member as a unique individual. Unity in both senses must be imposed on what is in itself non-unified in order to produce the determinate structure of whole and part. ${ }^{36}$ The possibility of identifying an individual as part of such a collection must thus result from the combination of a principle of Unity, in both senses, with a contrasting principle of the indefinitely many or multitudinous. This is what Plato calls in the Parmenides the

\footnotetext{
${ }^{33}$ Sayre (2005), p. 124.

${ }^{34}$ Sayre (2005), p. 126.

${ }^{35}$ Sayre (2005), pp. 125-26.

${ }^{36}$ Sayre (2005), p. 64.
} 
apeiron plethos and which, Sayre suggests, can also be identified with the (later) mentions of the "indefinite dyad" or, indeed, the "Great and the Small" of which Aristotle speaks.

On this basis, Sayre can argue that the final Philebus account of forms and participation involves a twofold application of the imposition of Unity on the Great and Small: first, in order to produce the determinate forms themselves, and second, in the imposition of the forms thus produced, now functioning as "measures", on the Great and Small again to produce the characteristics of particular sensible objects. ${ }^{37}$ If this is right, both the Forms and sensible things are composed from the two principles, although according to different modes of combination. This suggestion of a unitary genesis ultimately underlying both the forms and their sensory participants allows Sayre to contest both of two

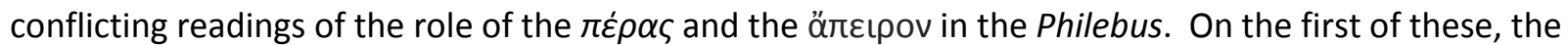
relationship between limit and the unlimited is analogous to or anticipatory of Aristotle's account of form and matter; here, the unlimited is accordingly said to be a kind of undetermined potentiality of objects to acquire certain properties. ${ }^{38}$ On the second existing view, the "unlimited" is not attributed directly to objects at all, but is rather a set of concepts which admit of variation as less or more. ${ }^{39}$ Sayre argues that both views have potentially fatal internal problems. The first, in particular, has difficulty explaining why the imposition of Unity should produce particular objects that are in some sense valued as ordered as opposed to bad or disordered elements corresponding to other points on the same continuum. But the second has difficulty explaining how the mixing of Unity and the Indefinite could produce determinate individuals and not simply determinate types. Both existing alternatives, Sayre argues, are furthermore difficult to square with the text. A better alternative is to construe the combination of Unity with the äreเpov as having the twofold application, both to the generation of forms and, once again, to the specification of particular objects, that Aristotle also suggests in his own gloss on Plato's theory of forms and numbers. In each case, the combination allows for determinate measure to be imposed upon what would otherwise be the ärદıрov character of what would become or change indefinitely and without limit.

\section{The Structure of Plato's Duality}

As we have seen, the dualism of the One and the Unlimited Dyad, if indeed it can be attributed to Plato and has roughly the structure that Stenzel, Becker, Lautman, and Sayre suggest, plausibly underlies a uniform Platonic account of ideal structural genesis. According to this account, both ideas and their participants, and even the underlying structure of their becoming in the "now", have their genesis in the interaction of the two "principles" ( $\dot{\alpha} \rho x \alpha i$ ) of the dualism. This raises the pressing question of the relationship of this "two" to the "one" of being which Deleuze affirms as the univocity of being, and relates to his ontology of difference. To address this question on the level of a formal and meta-formal analysis, we will first briefly underline several structural features that constrain the interpretation of Platonic dualism as we have reconstructed it here, following the contemporary commentators.

Plato's dualism, which is literally a dualism of the One and the Two, is a dualism of a radical and unfamiliar kind, as can be brought out by contrasting its structure with that of some more familiar ontological proposals. First, it is not a dualism of substances or types of entities. Neither is it the "twoworlds" dualism of vulgar Platonism (and vulgar anti-Platonism), which stop with the first distinction between a form and its sensible participant without pushing on, as Plato's dualism does, to the question

\footnotetext{
${ }^{37}$ Sayre (2005), p. 180.

38 Sayre (2005), p. 137.

${ }^{39}$ Sayre (2005), p. 139.
} 
of the ground of the identity and difference of the two terms that are thereby related. Again, given its structure, Plato's duality cannot be understood as the duality of two mutually complementary parts within a larger given whole, or of an opposition of forces which could, even in principle, be reconciled or reinscribed into a larger unity. (It may be that it can, however, be understood as the affirmation of the impossibility a priori of such a final synthesis, a point to which we will return.)

Both familiar dualisms, and even familiar cases of duality, consist in pointing out two things: two types of things in the case of dualism, two complementary parts of something in the case of intratheoretical dualities. Plato complicates this in perhaps the most decisive way possible in a single move. The "two" that he asks about are the two consisting (first) of the one and (second) of the two. This "second," moreover, is itself irreducibly dual: paradoxically split, in a way that affirms unlimited becoming in both of two opposed directions, and can thus in itself find no stopping point, on pain of not being what it is. This is sufficient to ensure that, even if the two "principles" of the one and the dyad are thought together, the thought will itself be irreducibly dual and dualizing. Rather than inscribe them within a single static field, or subsume them to the principle or possibility of a higher reconciliation, their work, if they really are ópxai, will include a rebound upon the discourse and even the thought that, naming them, claims to get a synoptic view of them. Whether this application of the Two to its own thought ruins the possibility that any articulable dualism can be true or any true dualism articulable, is a question to which we will return (in a twofold way) in the final section.

At the same time, and for the same reason, the inscription of the One as one element of the dyad in the Platonic dualism does not in any way indicate an incipient or approximate monism of the One. If the Platonic dualism indeed affirms the possibility of a uniform accounting for both being and becoming, it is not because it reduces the two to any given one. It is rather essential to its structure that it affirm an irreducible basis for both in the two principles it introduces, without any possible reduction of their difference, and it is in this way that it plausibly witnesses Plato's final overcoming of Eleaticism, while also subverting in advance any neo-Platonic reduction to the One. Indeed, because of (what we might call) the irreducibly "dyadic" character of the dyad, there is no possible deduction or derivation of it from the contrasting principle of the One. And although, as is witnessed in the complex dialectics of the Parmenides, the idea of an irreducible alterity may yield a profound sense of the difference, the duality that is at stake here is not simply the opposition of the One and the Other(s). In treating the dyad as a principle opposed to the One, Plato articulates a more structurally complex configuration of relationality in which any relativity of the other(s) to the One, if it is not to lead to a false correlation of the two, must be redoubled with an incommensurable counter-correlativity from the side of the Dyad. ${ }^{40}$

Thus by contrast with, for instance, the Aristotelian relativity of matter to form, or the Schellingian/Hegelian "identity of identity and difference," here, through the very dyadic character of the dyad, the dualism of the One and what is other to it is in no way overcome, suppressed, reduced or sublated by the assumption of an existing One-All. Rather than being overcome in such a way, dualism is rather apportioned, continually rediscovered, and deployed more aggressively, not only on the "ontological" level of entities but also on the level of the very logic of the account which systematically inscribes it in the structure of what is, without tacitly reinscribing it within a single total and consistent

\footnotetext{
${ }^{40}$ It may be possible to read the split names of Being in the Sophist in precisely this way, so that neither naming the One as Rest correlative to Motion nor naming the Dyad as the Different correlative to Identity succeeds in articulating a relation between the identity of the One and the motion of the Dyad. At the same time, the reappearance of two different, unrelated, relations in the place where one tries to get one to work for all would then succeed in showing something of the split "ontological difference" which cannot there (despite the new possibilities opened up by a "parricide" which yet remains Eleatic) be explicitly affirmed.
} 
system. Here, what Hegel identifies as the flaw of indeterminate negation is seen to be rather the form in which truth of duality as final: the relation by which an opposed $A$ and $B$ can be fixed and projected into a synthetic $A B$ turns out to be merely an $A B$ in the sense of $A$ or an $A B$ in the sense of $B{ }^{41}$

Because of the formal level on which the dualism operates, viz., not only intratheoretically, but metatheoretically, it is such as to split not only the ontological field to which it is applied, but also the theoretical position from which it finds any possible application. In this respect it reflexively takes itself up within its own scope, inscribing an irreducible two not only on the level of the principles grounding being and becoming, but also (as a "metalogical" or "metaformal" duality between completeness and consistency) on the level of any possible application of principles to being and the norms that govern it. $^{42}$

In particular, if "two" here is not just the quantity of the principles, as in Aristotle's doxography, but the very essence of a split ápxń, then any argument for limiting the possibilities of knowledge's access to principles as such, which does not make essential use of the duality, risks missing the intrinsic logic of the topic. Thus, one can emphasize completeness, underscoring that the two together generate all things. This produces a total system, which happens to rest on two principles. But this would simply be another theory of everything, as though instead of a one-all, we had here simply a two-all. This is the line of many who refer to ideal genesis, including, for instance, many of those who follow the "systematic" reconstructions of the Tübingen school. And it is also, of course, a tendency of Plato's thought. ${ }^{43}$ But the difference from monism is then only momentary and superficial, and nothing is easier than for improvers of the system, beginning with Neoplatonism, to repair lapsed monism by representing multiplicity and its disasters, the very stuff of existence according to the dualist account, as merely privative. Or one can emphasize consistency, pointing to how the "two" of the dualism together provide, in any concrete case, a coherent account of the determinate being of a thing. But this is to ignore or deny the inconsistency inherent to its becoming, its tendency to overleap boundaries and subvert identities through the continuity of its potentially limitless change in both directions, and thus to communicate directly, in the most banal of its changes, with infinite multiplicities that exceed the resources of a given consistent theory. Beyond either of these strategies, what is necessary to grasp the reflexive bearing of the Platonic duality on the very structure of ápxń as such is, rather, to emphasize its tangled and iterative structure, whereby the one is doubled by its other only in order for any unity of the two to be split once more, and in unlimited fashion. A radically dualist ontology of the Platonic sort,

\footnotetext{
${ }^{41}$ Given the complicated structure this implies, relating (as we shall see) constitutive ideas of consistency, completeness, and negation, what kind of logic should be used to treat this structure formally? Since it is plausible that closely formally-related problems arise in the context of set theory, for example in connection with Russell's paradox, it may be that set theory or second-order logic can provide the requisite expressive power. See Livingston (2012), chapters 1 and 8, for instance, for one development of the connection of issues treated here as arising through Plato's dualism with Russell's paradox and related structures. At any rate, it seems likely that, whatever logic is adopted, an essential reference to crucial limitative and paradoxical results of metalogic or metamathematics will be needed to make formal sense of the structure.

${ }^{42}$ The idea of making essential interpretive and ontological use of a metalogical duality between completeness and consistency was introduced by one of the authors (Bova) in conversation with the other author (Livingston) around 2008, and is central to the argument of Bova (2015) (where an extended version of some of the remarks of the present section can also be found) for an ultimately-ethical recuperation of the Platonic dialectic on metalogical/metamathematical grounds. For another development, see Livingston (2012), especially chapter 1. ${ }^{43}$ There is nothing remarkable about the fact that systematic and ontotheological tendencies can be found in Plato. What is remarkable is that there are also points of resistance to those tendencies internal to the Platonic text, and not incidentally but at its heart.
} 
then, can only be maintained with a shift in the ontological function of knowledge. The task of ontology no longer takes the form of a progressive completion of a One-All, or a filling in the gaps of a total account of all the beings that is in itself capable of both completeness and consistency. Rather, the one and the all are simultaneously present to us, not as starting points for a deductive or genetic chain whose existence would tacitly neutralize their ontological potential, but as norms of theoretical construction. It is then only the reflective acknowledgement of a failure, at once mathematical and philosophical, to realize them simultaneously that leads us to posit the irreducibility of the dyad as what there must have been, such that the projected synthesis of consistency and completeness absolutely is not.

This makes possible a kind of dialectical analysis which has a wholly different tendency from Aristotelian essentialism, insofar as it inscribes in place of any harmonious unity between thought and being in adequate knowledge rather an irreducible conflict of the norms of completeness and consistency. This is a conflict which indeed plays itself out immanently in knowledge, allowing it thereby to participate essentially in the duality of the principles itself. The metalogical or metaformal theory that results, as much as it remains a theory of the ápxń, shares as many characteristics with an an-archy. If the One, in its duality, is here still identified with the Good, then Platonic dualism structurally demands a conversion which would here separate the Good from the ideal of the Perfect, blocking any possible ontotheology.

\section{Univocity and Dualism: Ontological Questions}

How, then, does Plato's irreducible "two" stand with respect to what Deleuze affirms, early in Difference and Repetition, as the only possible ontological proposition and finds at the basis of any possible formal/ontological articulation of the irreducibility of difference, the proposition that Being is said in a single sense? On this point, we conclude by offering two distinct suggestions, whose compatibility is itself a difficult question, and which arise from the overlapping but different perspectives of the two present authors.

\section{First suggestion: Deleuzian side}

If the univocity of being - the single sense of its saying -- were indeed thought here as an ontic first principle or an undivided ápxń, it would indeed deny or restrict the duality of the Platonic "two." It would re-inscribe them within a logic of simultaneous completeness and consistency, and vitiate the iterated difference in which the duality maintains itself, as we have argued, in being applied to itself along with whatever is and becomes. But in order to reconcile the univocity of being with the original duality at the ontological and metalogical basis of ideal genesis, and thereby distinguish it completely from any principle of ontological monism, it may be sufficient to recall the specification which Deleuze immediately gives it. This is the specification that, though being is said in one and the same sense, that of which it is said is nothing other than difference itself.

More specifically, Deleuze writes, "In effect, the essential in univocity is not that Being is said in a single and same sense, but that it is said, in a single and same sense, of all its individuating differences or intrinsic modalities." ${ }^{44}$ The several "formally distinct senses" which articulate these differences or modalities of difference are, at the same time, univocally affirmed and said in the same way, in terms of a being "equal" for all. In briefly tracing the history of the univocity of being, Deleuze finds that Scotus affirms it as being's neutrality with respect to the distinction of its finite and infinite modalities, while Spinoza does so by affirming unitary substance as distinct from the modes, and Nietzsche by affirming

\footnotetext{
${ }^{44}$ Deleuze (1968), p. 36.
} 
the repetition in which only difference returns. ${ }^{45}$ Each one thereby avoids an onto-theological unification of beings into the totality of a One-All, but only by affirming instead an irreducible duality or multiplicity of the ápxń itself, on the level of principles or of the differentiating modes of that of which univocal being is said. But if the ontological proposition of the univocity of being thus does not contravene, in each of these cases, the equal affirmation of an irreducibly split doctrine of determining modes, then maybe all that is needed to affirm a parallel separation, and thus to recover a Plato beyond or before the onto-theological closure, is to remove the priority marked in Plato's own thought by his identification of Unity with the good, and flatten the hierarchy it implies. To do this would be, instead of Plato's own preference for the One over the dyad, to hold the "two" of the Platonic duality rigorously equal and their priority undecidable, thereby affirming the equal right and power of the two with respect to the ideal and real genesis they effect.

Second suggestion: Platonic side.

The reflexive problem of the split application of the duality to itself must be given its due if it is to be answered satisfactorily. What can it mean to give one theory that holds it to be true and articulable that there are two ultimate principles, two a $p x \alpha$ i? There is a strong prima facie case that any such theory refutes itself, and this has led to a widespread prejudice against dualism in contemporary thought. For Plato's logic of the "one-over-many" does not seem to stop at the terms of any known duality. In order to say that there are two of something, we seem to need to make essential use of a unity which precedes and surpasses the duality. This poses no problem when speaking of, say, two cows. But when, in order to say that there are two ápxai, it appears that we must appeal to a single univocal concept of ápxń, we seem to approach a destructive interference of form and content. For, if we are in possession of such a concept, we can take it, in correspondence with the entirety of its extension, to be the higher genus which is the proper object of our philosophical attention. Thus the conditions for the articulation of a duality of ápxai seem to be incompatible with its truth, and it appears that a dualist theory must be either meaningless or self-refuting.

This relentless reassertion of totality in and by means of theory may indeed characterize any conceivable strictly intratheoretical dualities, and the way in which such dualities, however stark, tend to reinforce the one-all of the theory in which they appear. For this reason, it is important to emphasize the metalogical character of the duality of apxai. This theory, if true, shares the essential characteristic of formal theories with the expressive power of arithmetic: the one-all that seems demanded to make their questions sensible is subverted by the answers those questions receive. The objection to dualism can then be reversed and taken as a criterion of adequacy. If we take a dualism of ápxai seriously, ontologically and logically, then at some point that thesis, which seems to rest on our possession of a prior concept of $\alpha \rho x n$, has to step out of order and retroactively split that concept itself. The duality of the $\alpha \rho x \alpha i$ must retroact upon the concept of ápxń in a logical experience which, if it is to output the dyad, can only be negative, that is, the experience of the impossibility, a priori, of their synthesis.

The unity of the ápxń that we need in order to ask the ontological question is then only the unity of the problem - specifically, a problem about synthesizing the norms which appear ontologically as the one and the dyad, and metatheoretically as consistency and completeness. Metalogical difference or metalogical duality thus depends essentially on metalogical negation, and vice versa. This negation is ontologically affirmative, not in the manner of the extension of a concept, but in that of the truth of a theorem.

\footnotetext{
${ }^{45}$ Deleuze (1968), pp. 39-42.
} 
Lautman and Deleuze have taken some of the first steps toward such an ontological recognition of what metamathematics shows us, and have done so, crucially, in terms of an experience of the difference between problem and solution. However, the price of selecting this point of interface is that it may be necessary to curtail Deleuze's tendency, in suggesting that the One is only the univocity of difference, to project univocity beyond the threshold of the question or problem, celebrating rather the affirmation of difference as such and in itself. Along similar lines, it would apparently also be necessary to reconsider whether Deleuze, in dealing theory the power thus to decide between affirmation and negation, tends to leave without a place an ontological affirmation that takes the form, exactly, of a metalogical negation.

\section{Works Cited}

Aristotle. 1984. Metaphysics. Trans. W. D. Ross. In The complete works of Aristotle: the revised Oxford translation, edited by Jonathan Barnes. Princeton, N.J.: Princeton University Press.

Becker, Oskar. [1927] 1973. Mathematische Existenz: Untersuchungen zur Logik und Ontologie mathematischer Phänomene. Second, unaltered edition. Tübingen: M. Niemeyer.

Becker, Oskar [1931] 2007. "The Diairetic Generation of Platonic Ideal Numbers." New Yearbook for Phenomenology and Phenomenological Philosophy 7, 261-95.

Bova, John (forthcoming). The Idea of the Good: Metalogic Is Ethics. [Working Title] Doctoral Dissertaton at Villanova University.

Deleuze, Gilles [1968] 1994. Difference and Repetition. Trans. Paul Patton. New York: Columbia University Press.

Deleuze, Gilles [1969] 1990. The Logic of Sense. Trans. Mark Lester and Charles Stivale, ed. Constantin V. Boundas. New York: Columbia University Press.

Duffy, Simon. 2009. "The Role of Mathematics in Deleuze's Critical Engagement with Hegel", International Journal of Philosophical Studies, 17:4, 563-582

Duffy, Simon B. 2013. "Lautman's Concept of the Mathematical Real." In Deleuze and the History of Mathematics in Defence of the "New." New York: Bloomsbury Publishing Plc.

Gaiser, Konrad. 1963. Platons ungeschriebene Lehre; Studien zur systematischen und geschichtlichen Begründung der Wissenschaften in der Platonischen Schule. Stuttgart: Klett.

Kaufman, Eleanor. 2012. Deleuze, the Dark Precursor: Dialectic, Structure, Being. Baltimore: The Johns Hopkins University Press.

Lautman, Albert [1938] 2011. Essay on the Notions of Structure and Existence in Mathematics. Trans. by Simon Duffy. In Mathematics, Ideas, and the Physical Real (translation of Lés Mathématiques, les idées et le réel physique (Libraire Philosophique J. VRIN, 2006).), pp. 87-193. 
Lautman, Albert [1939] 2011. New Research on the Dialectical Structure of Mathematics. Transl. by Simon Duffy. In Mathematics, Ideas, and the Physical Real (translation of Lés Mathématiques, les idées et le réel physique (Libraire Philosophique J. VRIN, 2006).), pp. 197-219.

Livingston, Paul M. 2012. The Politics of Logic: Badiou, Wittgenstein, and the Consequences of Formalism. New York: Routledge.

Miller, Mitchell. 1995. "'Unwritten Teachings' in the 'Parmenides.'” The Review of Metaphysics 48, no. 3 (1995): 591-633.

Nikulin, D. V. 2012. "Plato: Testimonia et Fragmenta." In The Other Plato the Tübingen Interpretation of Plato's Inner-Academic Teachings. Albany: State University of New York Press.

Plato. 1975. The Statesman, Philebus, Ion,. Trans. Harold North Fowler and W. R. M Lamb. Cambridge, Mass.: Harvard University Press.

Plato. 1977. Cratylus, Parmenides, Greater Hippias, Lesser Hippias. Trans. Harold North Fowler. Cambridge, Mass.; London: Harvard University Press ; W. Heinemann.

Plato. 1977. Theaetetus ; Sophist. Trans. by Harold North Fowler. Cambridge, Mass.; London: Harvard University Press ; W. Heinemann.

Sayre, Kenneth M. 2005. Plato's Late Ontology: A Riddle Resolved. Second Edition. Parmenides Publishing. (First edition: Princeton U. Press, 1983). 